\title{
FRIDA KAHLO'S GHOST AT THE ALGONQUIN SINGING DOROTHY PARKER'S “I DON'T CARE WHAT'S WRITTEN ABOUT ME SO LONG AS IT ISN'T TRUE" WITH A MEXICAN ACCENT.
}

Surely you've noticed

that I loved to be photographed

and that in virtually

every photo

I look foreign to my locale

and foreign to my era. Here

I am again, centered in what furnishes

my unmaking,

ribbons of song, pure

184

prosthetic presence.

Wouldn't any photographer tell you

that the subject is most .

radiant

if pictured at the head of the table?

That's why I've come back to tell you

that the round table is an occultation.

We should break it down: its edges,

like those of the bed that holds the invalid

should fall abruptly away

so that the center of the

picture brooks no absence

and adorns its own legend. 